\title{
Regiões de saúde e escalas geográficas
}

\author{
Health regions and geographic scales
}

\author{
1 Faculdade de Ciência \\ e Tecnologia, Universidade \\ Estadual Paulista Júlio \\ de Mesquita Filho, \\ Presidente Prudente, Brasil. \\ Correspondência \\ R. B. Guimarães \\ Departamento de Geografia, \\ Faculdade de Ciências \\ e Tecnologia, Universidade \\ Estadual Paulista Júlio \\ de Mesquita Filho. \\ Rua Roberto Simonsen 305, \\ Presidente Prudente, SP \\ 19060-900, Brasil. \\ raulguimaraes@uol.com.br
}

\begin{abstract}
The present article aims to discuss how the socalled health regions have been organized in Brazil since the respective governing ruling was issued (NOAS - SUS 01/2001). In order to clarify this new context, the author emphasises such concepts as region and geographic scale. The regional division under this ruling is based on the regional planning concept underlying the country's territorial policies since the founding of the Brazilian Institute of Geography and Statistics (IBGE). However, the apportionment in health regions has been both a requirement for improving the Unified National Health System (SUS) and a qualitative change in the national health policy. It is necessary to move forward by relating the regional division to the issue of scale. What is at stake is whether the regionalization of health in Brazil represents an improvement in the mediations between the various scales in the SUS.
\end{abstract}

Regional Health Planning; Health Policy; Medical Geography
Raul Borges Guimarães ${ }^{1}$

\section{Introdução}

A Norma Operacional da Assistência à SaúdeNOAS - SUS 01/2001 (Portaria MS/GM n. 95. Diário Oficial da União 2001; 29 jan) - regulamentou as diretrizes gerais para a organização regionalizada da assistência à saúde no Brasil. Com base em sua segunda edição (NOAS/SUS 01/2002 - Portaria MS/GM n. 373. Diário Oficial da União 2002; 27 fev), os convênios entre o Ministério da Saúde (MS) e os demais níveis de governo consideraram as prioridades assistenciais de cada estado, subdividido em regiões e microrregiões definidas no Plano Diretor de Regionalização da Saúde (PDR).

Os módulos assistenciais de nível microrregional preconizados por essa norma operacional do Ministério da Saúde (MS) devem ser organizados no âmbito de municípios-sede capazes de ofertar um conjunto de ações de média complexidade para a sua própria população e para a população dos municípios a ele adscritos. Tal diretriz exige que todas as unidades da federação elaborem seus PDRs, explicitando-se o papel de cada município no sistema estadual de saúde.

Nos últimos dois anos, cada unidade da federação teve autonomia para definir a sua divisão regional, base necessária para a elaboração do plano diretor da assistência à saúde. No Estado de São Paulo, por exemplo, a delimitação das regiões de saúde obedeceu à divisão das Di- 
retorias Regionais de Saúde (DIRs), o que representou a manutenção da mesma lógica de organização do sistema público de saúde já em vigor.

Como a norma operacional em questão facultou autonomia às unidades da federação para estabelecer a sua própria divisão regional, cabe indagar em que medida esta provocou avanços na forma de organização dos serviços de saúde ou, simplesmente, reforçou a estrutura existente. Um outro aspecto que também merece atenção é o fato de a norma ter gerado uma diversidade muito grande de situações, uma vez que cada estado adotou o seu próprio critério. Ora, se a norma operacional visa ao fortalecimento da política nacional de saúde, como manter essa diretriz geral e, ao mesmo tempo, respeitar a autonomia dos entes federados?

O presente texto tem como objetivo central analisar o processo de regionalização da saúde no Brasil, diante desse novo cenário de direcionamento do investimento de unidades públicas de saúde, com base na NOAS - SUS 01/2001. Para isso, será preciso não perder de vista o papel do MS na indução de políticas de investimento, respeitando-se também a diversidade de divisões regionais que estão sendo geradas pelas unidades da federação. Um outro esforço faz-se também necessário: o de superação da compreensão predominante a respeito de alguns conceitos, principalmente o de região, o de hierarquização e de escala geográfica.

\section{O conceito de região da Norma Operacional de Assistência à Saúde}

Segundo a Portaria MS/GM n. 373, que regulamentou a NOAS, a região de saúde é a "base territorial de planejamento da atenção à saúde, não necessariamente coincidente com a divisão administrativa do estado, a ser definida pela Secretaria Estadual de Saúde, de acordo com as especificidades e estratégias de regionalização da saúde em cada estado, considerando-se as características demográficas, sócio-econômicas, geográficas, sanitárias, epidemiológicas, oferta de serviços, relações entre municípios, entre outras [...] Por sua vez, a menor base territorial de planejamento regionalizado, seja uma região ou uma microrregião de saúde, pode compreender um ou mais módulos assistenciais", definido, segundo a mesma portaria, como um "conjunto de municípios, entre os quais há um município-sede" (grifos nossos).

Apesar de a portaria não exigir coincidência com a divisão administrativa do país, ela confere às secretarias estaduais de saúde o papel de condução do processo de regionalização de cada estado federado, o que, na prática, estabeleceu o ordenamento jurídico do Estado brasileiro como estrutura geral da proposta. Além disso, conforme grifos nossos, a região de saúde concebida na NOAS sugere a delimitação de um espaço contínuo, que diz respeito a uma parte de alguma unidade da federação, e cuja lógica é determinada pela interdependência funcional e pela polarização de um determinado município-sede, com um raio de abrangência de outros municípios vizinhos por meio dos fluxos entre os serviços de saúde de suas aglomerações urbanas, envolvendo um conceito operacional com vistas à intervenção dos planejadores (a respeito do conceito de região de planejamento, ver Boudeville 1 ).

$\mathrm{Na}$ atual gestão do governo federal, cabe ao Departamento de Apoio à Descentralização diretamente vinculado à Secretaria Executiva do MS - a formulação da proposta de regionalização da política nacional de saúde. Apesar de haver um reconhecimento de que a formulação de tal proposta é um processo político, no qual a autonomia dos entes federativos deve ser garantida e as estruturas e os desenhos regionais já efetuados no processo de ordenamento regional do SUS (DIR, regionais de saúde, dentro outros) devem ser considerados, há um nítido posicionamento crítico em relação à implementação da NOAS. Os PDRs não conseguiram, até agora, oferecer referenciais seguros para orientar o perfil e a distribuição das unidades prestadoras de serviços de saúde, desde as mais simples unidades básicas de saúde às unidades hospitalares e laboratoriais mais complexas, uma vez que o perfil das necessidades e prioridades de saúde da população não deve ser determinado apenas pelas demandas dos prestadores de serviços. Muito mais do que isso, é preciso considerar as informações epidemiológicas mais relevantes que podem diferenciar as regiões do país, bem como as reivindicações da população, encaminhadas pelas entidades que representam os usuários nos Conselhos de Saúde.

Nesse contexto, a proposta de regionalização da saúde não deverá perder de vista o papel indutor do MS, buscando-se a eqüidade das oportunidades de todo cidadão e abrindose espaço para a realização das potencialidades de cada um - jovens, mulheres, idosos, negros, minorias étnicas, dentre outros.

É importante ressaltar que o processo de desenvolvimento do Brasil acumulou uma enorme experiência de ação do Estado no ordenamento territorial do país e deixou um legado que deverá ser considerado por qualquer política pública. Afinal, em termos de infra-estru- 
tura e de distribuição da base produtiva, o território herdado da política de desenvolvimento nacional é profundamente desigual.

Por sua vez, o autoritarismo político, que isolou por duas décadas os especialistas em planejamento da sociedade civil organizada, cristalizou a idéia de que o desenvolvimento é fundamentalmente econômico e distante da política. Contudo, o conceito original de desenvolvimento requer vontade política de olhar para os problemas sociais 2 , e o processo de regionalização da saúde não será diferente. A resposta às diversidades e desigualdades inscritas no território nacional exige criatividade no plano político. Para isso, é preciso fazer a relação entre os diferentes conceitos e as contribuições produzidas, historicamente, por vários intelectuais que subsidiaram as políticas territoriais do Estado brasileiro.

\section{Regiões brasileiras: do acontecer hierárquico ao acontecer solidário}

Quando se fala, no Brasil, de região, regionalização, redefinições regionais, logo nos vem à mente o mapa da divisão regional do IBGE (Instituto Brasileiro de Geografia e Estatística). Evidentemente esse forte viés traz implicações em termos de concepção de mundo. O conceito de região presente na NOAS não é diferente. Vejamos por quê.

O IBGE foi criado em 1937. Naquela época, coube a ele reeditar a Carta Geral do Brasil e dar apoio cartográfico ao censo de 1940. Não por coincidência, tal instituto surgiu num período histórico em que o crescimento econômico passava cada vez mais a ter o Estado como agente regulador - através da intervenção no sistema de crédito, política de crédito, política cambial, controle de preços, política tributária, fiscal e salarial, ou mesmo como produtor direto em setores básicos da produção (aço, minério de ferro, dentre outros).

Com base no conceito de região natural, introduzido no Brasil pelo professor Delgado de Carvalho em 1913, Fábio Guimarães (chefe da Seção de Estudos Geográficos do Conselho Nacional de Geografia - IBGE) propôs uma divisão regional do Brasil, em 1941, a qual é a gênese da base de organização dos dados censitários do país.

Segundo Guimarães 3, para que as regiões não fossem escolhidas arbitrariamente, era forçosa a obediência à disposição determinada pela natureza, de modo que cada uma delas apresentasse uma certa unidade de conjunto, resultante da correlação entre os diversos fatos geográficos que nelas se observassem. Seu problema era, sobretudo, o da determinação das regiões naturais mediante a interpretação e explicação das conexões existentes entre os "fatos geográficos”, a fim de definir os diversos quadros naturais.

A consideração desse conjunto exigiu a seleção e interpretação dos fenômenos ocorrentes no território nacional para a identificação dos "mais significativos", em torno dos quais se unificariam todos os outros. Como exemplo, a vegetação foi considerada de grande importância na caracterização regional, como uma síntese de outros fatores que seriam fenômenos do domínio da "Geografia Física".

As preocupações que embasaram a proposta de Guimarães ${ }^{3}$ diziam respeito à finalidade estatística que deveria possibilitar a comparação de dados ao longo do tempo. As regiões naturais apresentavam a vantagem da estabilidade relativa ao período das atividades humanas. Tais atividades entrariam apenas como confirmação dos resultados já obtidos pela "Geografia Física”, resolvendo dúvidas quanto à delimitação e à unidade que caracterizavam cada região.

Como essa divisão surgiu para dar suporte às políticas territoriais do Estado brasileiro, modificaram-se, para fins administrativos, as delimitações estabelecidas pelo quadro natural, adequando-as aos limites das unidades políticas em que se dividia o país. O problema, nesse caso, foi definir de que modo agrupar as diversas unidades políticas e quantos agrupamentos formar.

O trabalho foi feito mediante um estudo prévio das diversas propostas de divisão regional do Brasil adotadas pelas instituições oficiais. Tendo como base a análise dessas divisões regionais, Guimarães ${ }^{3}$ concluiu que a melhor proposta, fundamentada nas regiões naturais, era a que fora apresentada por Delgado de Carvalho, adotada inclusive nos programas de ensino de geografia da época. Esta divisão, em cinco grandes regiões naturais (norte, nordeste, leste, sul e centro-oeste), foi subdividida em zonas fisiográficas, caracterizadas por elementos de ordem humana, fundamentalmente estabelecidas por meio da divisão regional do Conselho Técnico de Economia e Finanças.

Os censos de 1940, 1950 e 1960 foram sistematizados mediante a referida divisão regional que, desde a sua origem, desenvolveu-se pautada em um conceito híbrido. De um lado, seguindo a tradição da escola francesa, considerou-se a região como uma evidência empírica, passível de mapeamento e identificação na paisagem e nas realidades físicas e culturais, tal como o método proposto por La Blache ${ }^{4}$. Toda- 
via, na prática, a proposta de divisão regional do IBGE teve a influência das idéias do geógrafo Richard Hartshorne. Para esse americano, de origem alemã, a região não se constitui um objeto em si mesmo, mas uma construção intelectual, segundo objetivos traçados pelos pesquisadores 5 , que, no caso brasileiro, eram os técnicos do IBGE responsáveis pelo planejamento territorial do país.

A influência da escola americana no IBGE intensificou-se na década de 1960 com a incorporação do aporte teórico-metodológico da denominada New Geography, também conhecida como geografia teorética. Como decorrência, a regionalização do país reforçou ainda mais o caráter técnico-operacional do conceito de região, visando ao intervencionismo do Estado no planejamento territorial.

Foi sob este enfoque que ocorreu uma primeira reforma da proposta de divisão regional do Brasil, em 1967, a partir da qual foi organizado o levantamento censitário de 1970 e 1980. Em primeiro lugar, foi extinta a grande Região Leste, composta por Minas Gerais, Rio de Janeiro, Espírito Santo, Bahia e Sergipe, criandose a grande Região Sudeste, com o desmembramento de São Paulo da grande Região Sul e o acréscimo dos Estados da antiga região, com exceção da Bahia e Sergipe, que se incorporaram à grande Região Nordeste. As zonas fisiográficas foram transformadas em mesorregiões e estas, por sua vez, subdivididas em microrregiões homogêneas. Procurou-se, como resultado, uma combinação entre os limites jurídicoadministrativos, os fatos sócio-econômicos e o quadro natural (Divisão do Brasil em Microrregiões Homogêneas. Rio de Janeiro: IBGE; 1968), correlacionados por meio de técnicas estatísticas e matemáticas.

Essa renovação não significou, porém, o rompimento com as influências francesas. Muito pelo contrário, os trabalhos de Rochefort 6 , Kayser 7 e George 8 - representantes da geografia lablachiana renovada, que ficou conhecida como "Geografia Ativa" - foram considerados, desde a década de 1960, na análise dos fluxos econômicos, das redes de comunicação e das áreas de influência dos principais centros urbanos. De acordo com essa abordagem, acreditava-se que seria possível organizar o espaço de maneira mais harmoniosa e equilibrada, por meio do planejamento regional; daí o termo "ativa", ressaltando o sentido de uma geografia da ação, que concebia a região como objeto de intervenção ${ }^{9}$. Atentos às transformações geradas no mundo pela urbanização e a industrialização a partir da segunda metade do século XX, os trabalhos desses autores conside- ravam o espaço como um campo de fluxos que confluíam para as cidades, que tendiam à constituírem-se em pólos regionais. A compreensão da formação regional deveria ser buscada no estudo da hierarquia urbana e do papel das cidades na hierarquia dos lugares e no comando do território.

Nesses termos, o IBGE reformulou, mais uma vez, a sua divisão regional com o objetivo de desenvolver o censo de 1991, valendo-se de uma redefinição conceitual dos agregados espaciais denominados de microrregiões homogêneas, em vigor desde 1969. A justificativa dessa revisão recaiu sobre o anacronismo das regiões homogêneas, em face das mudanças de padrão espacial da realidade brasileira (Plano Geral de Informações Estatísticas e Geográficas. Rio de Janeiro: IBGE; 1992). Passou-se a entender por mesorregião uma área individualizada em uma unidade da federação, que apresenta formas de organização do espaço definidas pelas seguintes dimensões: o processo social como determinante; o quadro natural como condicionante e a rede de comunicação e de lugares como elemento de articulação espacial. Essas três dimensões deveriam possibilitar que o espaço delimitado como mesorregião tivesse uma identidade regional, sendo esta entendida como uma realidade construída ao longo do tempo pela comunidade que aí se formou.

As microrregiões foram definidas como partes das mesorregiões que apresentavam especificidades quanto à organização do espaço: estrutura da produção agropecuária, industrial, extrativismo mineral ou pesca. Essas estruturas de produção diferenciadas puderam também resultar da presença de elementos do quadro natural ou de relações sociais e econômicas particulares, a exemplo, respectivamente, das serras úmidas nas áreas sertanejas, ou da presença dominante da mão-de-obra não assalariada numa área de estrutura social capitalista.

Apesar dessa tentativa de renovação do conteúdo da divisão regional, a identificação das microrregiões ocorreu por superposições sucessivas de dados constituídos pela produção, distribuição, consumo, incluindo atividades urbanas e rurais, numa macroestrutura estabelecida no gabinete dos planejadores, tendo em vista a modelagem estatística e os procedimentos técnicos desenvolvidos e acumulados pela chamada geografia teorética. Para o censo de 2000, o IBGE manteve esse mesmo procedimento, revendo algumas delimitações e/ou desmembrando microrregiões, com o cuidado de manter sua série histórica. O Estado de Tocantins, criado do desmembramento de Goiás, 
foi incorporado à Região Norte, em razão de suas características sócio-econômicas e ambientais amazônicas.

Diante do exposto, a divisão regional do IBGE, implicitamente, concebe a região como uma unidade espacial de intervenção e ação do Estado, cabendo ao planejador reconhecê-la, descrevê-la, tornar claros os seus limites. Concebe, ainda, a totalidade espacial como um somatório das partes, abstraindo-se as variáveis mais significativas para a identificação de suas características mais homogêneas. Tal delimitação dos núcleos regionais (cores) também se realiza mediante o processo de diferenciação entre os diversos lugares 10.

A proposta de regionalização presente na NOAS mantém essa tradição, digamos, "ibegeana”, já que a portaria ministerial define a região de saúde como um espaço político-operativo do sistema de saúde, no qual, por via institucional, é possível estabelecer maior sinergia entre os diferentes níveis de gestão dos serviços de saúde e enfrentar os entraves para o estabelecimento do comando único das ações de saúde. Essa ilusão tecnocrática também reforça uma tradição das políticas territoriais do Brasil, que sempre trabalhou com uma concepção hierárquica e geométrica da região. Trata-se de uma concepção hierárquica na qual há uma tendência à racionalização das atividades, que se faz sob o comando de uma organização que detém informações privilegiadas, sob a primazia das normas. É também uma concepção geométrica do espaço; parte-se do pressuposto de que os níveis crescentes de abrangência - dos módulos assistenciais aos territórios estaduais - referem-se a subtotalidades que comporiam a totalidade do espaço do SUS, como um imenso e complexo mosaico.

Dessa forma, assim como a idéia de região de saúde está fortemente relacionada com a divisão regional do IBGE, o preceito constitucional de hierarquização pode denotar um sentido de organização dos serviços de saúde no qual o nível superior é mais importante do que o nível inferior. Tal compreensão encontra raízes no próprio ordenamento jurídico do Estado brasileiro, especialmente após a proclamação da República, o que não representaria absolutamente nada de novo. Assim como nas políticas de saúde da Primeira República, que tiveram um papel importante na criação e no aumento da capacidade do Estado de intervir sobre o território nacional 11, a proposta de regionalização da saúde, em vigor, poderá representar apenas a presença e controle das instituições estatais sobre o território a partir do centro, da autoridade no plano nacional.
De fato, a política nacional de saúde tem como preceito constitucional a regionalização e a hierarquização dos serviços, considerandose a integração das ações em um sistema único de saúde nas três esferas do poder federativo, o que representou enorme conquista em termos da universalização do direito à saúde. Entretanto, a subordinação da divisão regional às políticas territoriais do Estado brasileiro, tal como no caso do IBGE, provoca distorções. A principal delas resulta da necessidade de moldar as regiões aos limites jurídico-administrativos dos estados e municípios da federação. Do ponto de vista estatístico, isso significa, não raras vezes, recortar um certo fenômeno cuja delimitação não respeita essas fronteiras. Acaba-se por subdividir elementos que fazem parte de um mesmo processo.

O momento político do país sinaliza para uma proposta de regionalização que não se transforme apenas numa unidade espacial de intervenção e controle do Estado. Muito mais do que isso, a divisão regional da política de saúde do Brasil deve ser expressão da pactuação entre os diversos atores envolvidos na gestão do setor, com base na diversidade de situações, arranjos e alternativas que estão sendo construídos pela sociedade para o fortalecimento da capacidade de gestão do SUS. Nesses termos, a região se impõe como um espaço de manifestação da solidariedade entre os parceiros que compartilham a gestão do sistema. Ela não existe sem disputa política e pode ser definida como o espaço de solidariedade e de sinergias necessárias para a concretização do SUS, em seu plano operacional.

A construção do significado do conceito de região passaria a se confundir, assim, com a busca por uma leitura política espacializada baseada em um modo consistente de expor as conexões entre as diferentes escalas, o que aproxima o debate a respeito das regiões de saúde da concepção dialética da totalidade. Essa abordagem nos remete a uma compreensão do conceito de região como parte e todo, ou seja, uma totalidade aberta e em movimento, que traz em si uma outra questão: a da escala geográfica 9 .

Nesse caso, parte-se do pressuposto de que a região é uma realidade empírica e, ao mesmo tempo, um recorte analítico para melhor compreensão da diferencialidade espacial. Conclui-se daí que a delimitação das regiões não se resume apenas a uma determinada escala cartográfica, definida geometricamente como uma relação de proporcionalidade entre o tamanho real da superfície terrestre e o seu tamanho representado no papel. Se fosse isso, a região seria, como é usualmente considerada, uma me- 
soescala entre o local e o nacional. Mas, na qualidade de uma resolução geográfica de processos sociais contraditórios de competição e cooperação, a escala geográfica regional é produzida pelas relações sociais dos atores políticos em jogo 12,13. Ou seja, a região não é um dado $a$ priori, porém está em disputa, assim como suas fronteiras demarcam a disputa social pelo lugar em torno do qual o poder é exercido e contestado.

Vejamos melhor essa idéia por meio de um exemplo.

Em 11 de setembro de 2001, dois aviões que partiram de Boston em direção a Los Angeles, nos Estados Unidos, foram seqüestrados e tiveram suas rotas alteradas. Os seqüestradores tinham como objetivo atingir as torres do World Trade Center, um dos maiores edifícios do mundo, localizado na Ilha de Manhattan, em Nova York. Para alcançar esse objetivo, certamente eles utilizaram mapas numa escala que permitia identificar facilmente o alvo e traçar uma nova rota de vôo.

Os seqüestradores, no entanto, não escolheram o World Trade Center por ele ser facilmente localizável quando visto do avião e com o uso de mapas. Esses edifícios eram os mais imponentes de Nova York, considerados um cartão postal de Manhattan, e abrigavam um grande número de escritórios de importantes empresas. Assim, ao destruir um simples ponto na escala cartográfica do mapa local, os seqüestradores conseguiram paralisar os Estados Unidos e derrubar as bolsas de valores em todo o mundo. Eles não estavam apenas utilizando a escala cartográfica, mas afetando o mundo na escala geográfica global. Dessa forma, foram capazes de transformar aquele acontecimento numa síntese de múltiplas escalas - a escala da vida cotidiana de Nova York, que entrou em colapso aquele dia; a escala do Estado americano, que se mostrou muito mais vulnerável do que se supunha aos ataques externos; a escala do mundo ocidental, que se viu diante de um "inimigo invisível"; a escala da revolução islâmica, que rompeu barreiras regionais e passou a adotar estratégias globalizadas; dentre outras.

É essa complexa síntese de escalas geográficas que definiu o peso político daquele acontecimento. Isto é, quanto mais uma ação resultar na articulação de múltiplas escalas, maior a sua importância política. No caso da regionalização da saúde brasileira, o que está em questão é se esse movimento representa ou não um aprimoramento das mediações entre as diversas escalas do SUS. Não se pretende delimitar mais um nível hierárquico de poder - o nível regional (uma quarta esfera de gestão?) - e, sim, instrumentalizar os parceiros do SUS para a co-gestão dos serviços, potencializando suas múltiplas articulações escalares.

Claro que a leitura dos mapas de diferentes escalas é importante para a delimitação das regiões, mas caberia ao MS a compreensão das articulações entre as escalas produzidas socialmente, identificando os grupos que exercem o controle e a mobilidade entre diferentes escalas.

Várias questões sociais ganhariam relevância regional, mesmo que não implicassem necessariamente fenômenos inscritos no território. Para isso, seria necessário considerar:

- as características que tornam coerente cada escala geográfica produzida socialmente (forças de cooperação);

- as diferenças internas de cada escala geográfica (forças de competição);

- as fronteiras entre as escalas geográficas em jogo e as possibilidade de saltar escalas (mecanismos de mediação).

Pensar a regionalização da saúde nesses termos encontra respaldo em autores da geografia brasileira amplamente utilizados na epidemiologia social. Milton Santos 14, por exemplo, tem Neil Smith como referência quando analisa a conceito de escala. Para este, a noção de evento tem um papel central na compreensão da produção da escala geográfica. Cada combinação de eventos num dado momento cria um fenômeno unitário que resulta na singularidade de cada lugar. Nesse sentido, a escala geográfica pode ser fundida com a escala do acontecer ou da realização dos fenômenos no nível local, ou seja, a produção social da escala é uma fusão do tempo e do espaço, da geografia com a história. Essa escala das relações cotidianas no espaço banal se articula com um outro nível escalar fundamental, que é a escala do comando e do controle cada vez mais globalizado.

Responder a tal desafio exige a leitura crítica dos dados existentes e que estão sendo gerados com base nos PDRs da saúde das unidades da federação, definindo-se com maior clareza as diretrizes, as estratégias e as prioridades de ação em cada unidade regional, de acordo com a NOAS em vigor (NOAS - SUS 01/2002). Igualmente importante é o esforço de considerar a coerência entre o conceito de região adotado e as outras estratégias espaciais da política nacional de saúde, particularmente aquelas baseadas na categoria território. 


\section{Regionalização da saúde e seus nexos com outras estratégias espaciais}

Como dissemos, o território tem se constituído em uma das principais categorias da estratégia espacial da política nacional de saúde. Em primeiro lugar, o processo de descentralização desencadeado pela reforma sanitária brasileira adotou como estratégia a municipalização dos serviços de saúde e a integração das ações, com comando único em cada nível de governo. Nesse caso, o território é visto como uma área, delimitada por fronteiras políticas, cujo poder público local é soberano diante de um conjunto de questões acordado pelo pacto federativo. Sob esse prisma, a mudança de nível no SUS referese a uma mudança de ordem qualitativa. Quer dizer, do local para o nacional, perdem-se detalhes, mas ganham-se informações de conjunto, mais gerais, ampliando-se a compreensão do todo, a capacidade de visão e de formulação estratégica. Isso não quer dizer, todavia, que o nível nacional seja mais importante do que os níveis inferiores, uma vez que o nível local é a escala em que a política de saúde ganha capilaridade na vida cotidiana dos cidadãos brasileiros e, por isso, capacidade operacional.

Coerente com esta abordagem regional que se quer implantar na política nacional de saúde, o conceito de hierarquização refere-se apenas ao nível de complexidade dos serviços oferecidos à população, organizados em unidades regionais que articulam os três níveis de poder - municipal, estadual e federal. As questões políticas que envolvem esse ordenamento jurídico do SUS chamam a atenção para a discussão das relações entre o Estado, o poder e a democracia, considerando-se os movimentos sociais e suas escalas geográficas de ação. Esse fato torna a experiência brasileira da reforma sanitária brasileira um exemplo de movimento sócio-territorial, visto que estabeleceu a constituição do território como um trunfo da luta política (a respeito do conceito de movimento sócio-territorial, ver Fernandes 15).

Por causa disso, a concepção de espaço presente na política nacional de saúde é muito mais do que uma extensão geométrica utilizada meramente para a administração dos serviços de saúde. Muito pelo contrário, a saúde pública, por meio da expansão de seus serviços, está inserida no tecido urbano e é parte constitutiva da divisão social e técnica do trabalho. Na qualidade de locus do trabalho médico articulado às redes cada vez mais complexas de produção e consumo, a saúde é um campo no qual as relações sociais são baseadas em políticas de classe. Em vista disto, ela deve ser conti- nuamente analisada no contexto da economia política da urbanização 16 .

Em resumo, há profundas implicações de geografia política na saúde pública. Dentre elas, destacamos:

- a definição de quem exerce poder e disputa a agenda da política de saúde pública, interferindo nos poderes da soberania da nação-estado; - a compreensão dos projetos políticos dos atores sociais que atuam na saúde pública, considerando contradições e conflitos de interesse no interior do estado;

- a delimitação de espaços de poder, bem como as ações coletivas adotadas e sua relação com determinados padrões de espacialidade da política, forjados seja no discurso, seja nas práticas em saúde pública.

É por causa dessas características que o território concebido e, ao mesmo tempo, em processo de construção pela política nacional de saúde é muito mais do que a extensão territorial dos municípios brasileiros. Várias outras estratégias espaciais, que apresentam a territorialização como um trunfo político, poderiam ser enumeradas - como a delimitação das áreas de abrangência das unidades de saúde, os distritos sanitários ou os programas de saúde da família 17. Em todas essas experiências, o processo de territorialização do SUS está produzindo uma diferenciação entre espaços da vida cotidiana, que poderia ser reconhecida como um processo de regionalização em diferentes escalas.

Considerando esses pressupostos, a distinção entre região e território passa a ser menos relevante, desde que a compreensão da totalidade não perca de vista que o SUS é um "acontecer solidário", nos termos postos por Santos 18, chamando a atenção da sociedade brasileira para a realização compulsória de tarefas comuns em torno da vigilância à saúde. Isto é, com base nessa abordagem de região, é uma ilusão pretender trabalhar valendo-se de conceitos puros. O mais importante é considerar a relação indissociável entre a representação e o real que se quer decifrar, que está em permanente movimento.

Conclui-se, dessa forma, ser esse um dos maiores desafios da formulação de uma proposta de regionalização da saúde no Brasil. Como respeitar a autonomia de cada unidade federativa em sua adequação à regionalização desencadeada pela NOAS - SUS 01/2001 e, ao mesmo tempo, romper os limites jurídico-administrativos da base estatística, desagregando a informação no nível que cabe ao fenômeno social? Em outras palavras, como desenvolver uma metodologia que nos permita trabalhar as 
informações geradas pela regionalização da saúde, com base na norma operacional em vigor, sem perder de vista a possibilidade de outros recortes, seja de origem territorial, seja do ponto de vista de outros parâmetros de natureza epidemiológica, seja de organização dos serviços, resultando no entendimento do conteúdo dinâmico das redefinições regionais?

\section{Considerações finais}

A história recente da descentralização da saúde já demonstrou que a NOAS não é suficiente para incentivar mecanismos de co-gestão regional do SUS. Como um meio e, ao mesmo tempo, um resultado da produção social da democracia brasileira, qualquer proposta de regionalização da saúde no Brasil deverá contribuir para o fortalecimento da identidade local e de um determinado território no qual o poder político-institucional é exercido por um amplo conjunto de atores sociais envolvidos.

A política nacional de saúde é um bom exemplo da criatividade da sociedade brasileira para encontrar as suas próprias alternativas (o modelo de gestão do SUS não encontra nenhum paralelo no mundo). Mas é impossível avançar sem integrar essa proposta com outras iniciativas de regionalização em andamento em outros ministérios e instâncias do governo, integrando esforços para diminuir a pobreza, a de-

\section{Resumo}

O presente artigo tem como objetivo central discutir o processo de regionalização da saúde no país, considerando-se o novo cenário de direcionamento do investimento de unidades públicas de saúde, a partir da publicação da Norma Operacional de Assistência à Saúde (NOAS - SUS 01/2001). Para isso, um esforço faz-se necessário: o de superação da compreensão predominante a respeito de alguns conceitos, principalmente o de região e de escala geográfica. A proposta de divisão regional dessa NOAS baseia-se no conceito de região de planejamento que, desde a fundação do Instituto Brasileiro de Geografia e Estatística, tem subsidiado as políticas territoriais do Estado brasileiro. Contudo, a regionalização da saúde no Brasil é uma necessidade para o fortalecimento do SUS e uma mudança qualitativa da política nacional de saúde. É preciso avançar, relacionando a divisão regional do Brasil com a questão da escala. O que está em questão é se a regionalização da saúde brasileira representa ou não um aprimoramento das mediações entre as diversas escalas do SUS.

Regionalização; Política de Saúde; Geografia Médica sigualdade e a exclusão social. O Brasil terá que encontrar alternativas para distribuir melhor a renda, diminuir o desemprego e aumentar o acesso à saúde e ao saneamento básico, dentre muitas outras prioridades.

Cada segmento social envolvido nesse processo tece suas próprias redes e nexos territoriais, guardando em si um certo grau de indeterminação. O caráter anárquico (o que não quer dizer caótico) dessas redes tecidas pela sociedade dá ao fenômeno das redefinições regionais feições de uma trama multifacetada, com diversos níveis de matizes e modalidades de circulação, distribuição e consumo, inexplicáveis num único nível escalar. Daí a urgência de uma proposta de regionalização mais efetiva, que avance de forma clara na direção do princípio constitucional de hierarquização e regionalização dos serviços de saúde. Se o processo de tomada de decisão no nível local deu maior concretude à política nacional de saúde, considerar o município isolado de seu contexto regional resulta num processo inverso do esperado. O município per si é uma mera abstração, uma vez que está inserido em diferentes formas de articulação escalar.

Conforme deixamos claro desde a primeira página do texto, para discutirmos a regionalização da saúde no Brasil, é preciso rever alguns conceitos que envolvem essa tarefa, relacionando-os com as diretrizes políticas de tal proposta.

\section{Agradecimentos}

Agradeço as contribuições do Grupo de Trabalho de Cartografação das Regiões de Saúde do Brasil, sob a coordenação do Dr. Nilo Brêtas, do Departamento de Informação e Informática do SUS/Ministério da Saúde/Secretaria Executiva/Governo do Brasil. 


\section{Referências}

1. Boudeville JR. Aménagement du territoire et polarisation. Paris: M.-Th. Génin; 1972.

2. Arbix G, Zilbovicius M, Abramovay R. Razões e ficções do desenvolvimento. São Paulo: Editora UNESP; 2001.

3. Guimarães F. Divisão regional do Brasil. Revista Brasileira de Geografia 1941; 3:318-73.

4. Claval P. Histoire de la géographie. Paris: PUF; 1995.

5. Hartshorne R. Propósitos e natureza da geografia. São Paulo: Editora Hucitec/Edusp; 1978.

6. Rochefort M. Métodos de estudos de redes urbanas. Boletim Geográfico 1961; 19:3-18.

7. Kayser B. A região como objeto de estudo da geografia. In: George P, organizador. Geografia ativa. São Paulo: Difusão Européia do Livro; 1968. p. 279-321.

8. George P. A ação do homem. São Paulo: Difusão Européia do Livro; 1968.

9. Lencioni S. Região e geografia. São Paulo: Edusp; 2003.

10. Guimarães RB. Produção do espaço e (re)definições regionais: um jogo de palavras? In: Melo JG, organizador. Região, cidade e poder. Presidente Prudente: Grupo de Pesquisa Produção do Espaço e Redefinições Regionais; 1996. p. 33-42.
11. Hochman G. A era do saneamento. São Paulo: Editora Hucitec/ANPOCS; 1998.

12. Smith N. Geography, difference and the politics of scale. In: Doherty J, Graham E, Malek M, editors. Postmodernism and the social science. London: Macmillan; 1992. p. 50-95.

13. Smith N. Contornos de uma política espacializada: veículos dos sem-teto e produção de escala geográfica. In: Arantes A, organizador. O espaço da diferença. Campinas: Papirus; 2000. p. 132-75.

14. Santos M. A natureza do espaço: técnica e tempo, razão e emoção. São Paulo: Editora Hucitec; 1996.

15. Fernandes B. Movimento social como categoria geográfica. Terra Livre 2000; 15:59-85.

16. Singer P. Prevenir e curar: o controle social através dos serviços de saúde. Rio de Janeiro: Forense Universitária; 1978.

17. Monken M, Barcellos C. Vigilância em saúde e território utilizado: possibilidades teóricas e metodológicas. Cad Saúde Pública 2005; 21:898-906.

18. Santos M. A natureza do espaço: técnica e tempo, razão e emoção. São Paulo: Editora Hucitec; 1996

Recebido em 29/Jun/2004

Versão final reapresentada em 21/Out/2004

Aprovado em 09/Nov/2004 